\title{
Persepsi Siswa Kelas XI Terhadap Pengelolaan Kegiatan Ekstrakurikuler Kepramukaan Di SMK Negeri
}

\author{
Lola Yolanda 1, Nelfia Adi 2, Hanif Al Kadri 3, Anisah 4
}

1,2,3,4 Administrasi Pendidikan, Universitas Negeri Padang

Lola Yolanda ${ }^{1}$, e-mail: lolayolanda08@gmail.com

Nelfia Adi², e-mail: nelfiaadi@fip.unp.ac.id

Hanif Al Kadri³, e-mail: hanifalkadri@fip.unp.ac.id

Hanif Al Kadri', e-mail: anisah@fip.unp.ac.id

\begin{abstract}
This research is a quantitative descriptive study, with the aim of obtaining information about the Perceptions of Class XI Students on the Management of Scouting Extracurricular Activities at SMK state. The population of this research is all class XI totaling 469 students, the technique used is Proportional Random Sampling with a sample of 87 students. The instrument used was a questionnaire in the form of a Likert scale. The results showed that 1) the students' perceptions seen from the planning aspect of scouting extracurricular activities were in the good category with a score of 4.00; 2) Students' perceptions seen from the organizational aspect were categorized as good with a score of $4.01 ; 3$ ) Judging from the aspect of scouting extracurricular activities in the good category with a score of $3.83 ; 4$ ) and student perceptions seen from the aspect of supervision are in the good category with a score of 4.05 . So it can be concluded that students' perceptions of the management of scouting extracurricular activities at SMK state were classified as good with a score of 3.97.
\end{abstract}

\begin{abstract}
Abstrak
Penelitian ini adalah penelitian deskriptif kuantitatif, bermaksud memperoleh informasi tentang Persepsi Siswa Kelas XI Terhadap Pengelolaan Kegiatan Ekstrakurikuler Kepramukaan di SMK Negeri. Populasi penelitian ini yaitu seluruh kelas XI berjumlah 469 siswa, teknik yang digunakan yaitu Proportional Random Sampling dengan hasil sampel 87 siswa. Instrumen yang digunakan yaitu angket dalam bentuk Skala Likert. Hasil penelitian menunjukkan bahwa 1) Persepsi siswa dilihat dari aspek perencanaan kegiatan ekstrakurikuler kepramukaan tergolong kategori baik dengan skor $4,00 ; 2)$ Persepsi siswa dilihat dari aspek pengorganisasian terkategori baik dengan skor 4,$01 ; 3$ ) Dilihat dari aspek pelaksanaan ekstrakurikuler kepramukaan berada pada kategori baik dengan skor $3,83 ; 4)$ dan persepsi siswa dilihat dari aspek pengawasan berada pada kategori baik dengan memperoleh skor 4,05. Jadi dapat disimpulkan persepsi siswa terhadap pengelolaan kegiatan ekstrakurikuler kepramukaan di SMK Negeri tergolong baik dengan skor 3,97.
\end{abstract}

Kata Kunci: Management of scouting extracurricular activities

How to Cite: Yolanda, Lola 1, Nelfia Adi 2, Hanif Al Kadri 3, Anisah 4, 2021. Persepsi Siswa Kelas XI Terhadap Pengelolaan Kegiatan Ekstrakurikuler Kepramukaan di SMK Negeri. Journal Educational Administration and Leadership, Vol (N): pp. XX-XX, DOI:10.24036/XXXXXXXXXX-X-XX

\section{Pendahuluan}

Pendidikan merupakan usaha sadar dan terencana dalam mengembangkan kemampuan spiritual, pengendalian diri, kecerdasan, kepribadian, akhlak mulia serta bermanfaat bagi masyarakat, bangsa dan negara. Pendidikan merupakan faktor dalam keberlangsungan kehidupan karena dapat meningkatkan kecerdasan, keterampilan, mengembangkan kompetensi diri, pembentukan pribadi yang bertanggung jawab, dan kreatif.

Dalam mencapai tujuan pendidikan tidak bertumpu pada program persekolahan tetapi juga pada kegiatan ekstrakurikuler. Ekstrakurikuler bertujuan untuk memperdalam, memperluas wawasan siswa, memperkenalkan keterkaitan dengan materi pembelajaran, mengembangkan skill siswa, menyalurkan minat 
Terbit online pada laman web jurnal: http://jeal.ppj.unp.ac.id

bakat. Pendidikan formal di sekolah terdiri atas kegiatan intrakurikuler dan ekstrakurikuler. Kegiatan intrakurikuler dilakukan di dalam jam sekolah dan ekstrakurikuler di luar jam sekolah.

Berdasarkan (PERMENDIKBUD R.I No.62 Tahun 2014, 2014) "Kegiatan ekstrakurikuler dibagi menjadi dua yaitu ekstrakurikuler wajib dan ekstrakurikuler pilihan, seperti pramuka, PMR, Rohis dan lainnya. Yang akan dibahas dalam penelitian ini adalah pramuka. Pramuka merupakan kegiatan ekstrakurikuler wajib sesuai ditetapkan dalam Undang-Undang (Republik Indonesia, 2010) dan (KEMENDIKBUD RI, 2014)

Kegiatan ekstrakurikuler mampu membentuk siswa menjadi manusia yang berkepribadian dan berwatak luhur serta tinggi mental, moral, budi pekerti, dan keyakinan dalam beragama, selain itu melatih siswa menjadi disiplin, tanggung jawab, sosial, cinta alam, mandiri, dan melatih menjadi seorang pemimpin.

Berdasarkan observasi yang dilakukan di SMK Negeri, penulis menemukan masalah-masalah yang terjadi didalam pengelolaan kegiatan ekstrakurikuler kepramukaan terlihat dari fenomena-fenomena yang ditemui dalam pengelolaan ekstrakurikuler kepramukaan yaitu: 1) Masih adanya kegiatan ekstrakurikuler kepramukaan yang telah dirancang namun masih belum terlaksana sebagaimana mestinya; 2) Masih kurang jelasnya pembagian kerja didalam struktur organisasi kepramukaan. Hal ini terlihat dari anggota-anggota pada setiap struktur organisasi belum bekerja sesuai dengan tupoksinya, sehingga mengakibatkan kurang optimalnya pelaksanaan kegiatan ekstrakurikuler kepramukaan di sekolah tersebut; 3) Pelaksanaan ekstrakurikuler kepramukaan belum sesuai dengan rencana program sekolah. Hal ini terlihat pada saat pelaksanaan latihan rutin mingguan sering terjadinya keterlambatan latihan kepramukaan berakibat pelaksanaan kegiatan tidak sesuai dengan jadwal: 4) Kurangnya pengawasan yang dilakukan oleh pembina terhadap pelaksanaan kegiatan ekstrakurikuler kepramukaan. Terlihat dari adanya siswa yang melaksanakan kegiatan lain disaat ekstrakurikuler dilaksanakan dan masih banyak siswa yang tidak mengikuti kegiatan tersebut.

\section{Metode Penelitian}

Penelitian ini adalah penelitian deskriptif bermaksud untuk memperoleh informasi mengenai persepsi siswa kelas XI terhadap pengelolaan kegiatan ekstrakurikuler kepramukaan di SMK Negeri. Populasinya adalah seluruh siswa kelas XI. Teknik penarikan sampel yaitu menggunakan Proportional Random Sampling memperoleh sampel 87 siswa. Sedangkan instrumen yang digunakan yaitu angket/kuesioner dengan lima alternatif jawaban dalam bentuk Skala Likert.

\section{Hasil dan Pembahasan}

Hasil dan Pembahasan Penelitian Persepsi Siswa Kelas XI Terhadap Pengelolaan Kegiatan Ekstrakurikuler Kepramukaan Di SMK Negeri dapat dilihat dari masing-masing indikator, yaitu:

a. Perencanaan Kegiatan Ekstrakurikuler Kepramukaan di SMK Negeri Tabel 1. Distribusi Data Perencanaan Kegiatan Ekstrakurikuler Kepramukaan

\begin{tabular}{|c|c|l|c|c|}
\hline No & Indikator & \multicolumn{1}{|c|}{ Sub Indikator } & Rata-rata & Kriteria \\
\hline \multirow{4}{*}{1} & \multirow{4}{*}{$\begin{array}{c}\text { Perencanaan kegiatan } \\
\text { ekstrakurikuler } \\
\text { kepramukaan }\end{array}$} & $\begin{array}{l}\text { Menyusun program kegiatan } \\
\text { ekstrakurikuler kepramukaan. }\end{array}$ & 4,15 & Baik \\
\cline { 3 - 5 } & $\begin{array}{l}\text { Bentuk kegiatan yang } \\
\text { diselenggarakan }\end{array}$ & 4,22 & Baik \\
\cline { 3 - 5 } & Sumber daya yang diperlukan & 3,92 & Baik \\
\cline { 3 - 5 } & $\begin{array}{l}\text { Kebutuhan, potensi, dan minat } \\
\text { peserta didik }\end{array}$ & 4,00 & Baik \\
\cline { 3 - 5 } & Sumber daya pelatih /instruktur & 3,69 & Baik \\
\hline \multicolumn{2}{r|}{ Rata-rata } & $\mathbf{4 , 0 0}$ & Baik \\
\hline
\end{tabular}

Hasil pengolahan data perencanaan kegiatan ekstrakurikuler di SMK Negeri memperoleh skor ratarata tertinggi pada sub indikator perencanaan kegiatan ekstrakurikuler kepramukaan adalah pada menyusun bentuk kegiatan yang diselenggarakan dengan skor 4,22 tergolong baik dan skor terendah berada pada sub indikator perencanaan kegiatan ekstrakurikuler kepramukaan adalah pada menyusun perencanaan untuk mendatangkan pelatih dalam kegiatan ekstrakurikuler dengan skor 3,69 berada pada kategori baik.

Ini berarti bahwa perencanaan bentuk kegiatan yang diselenggarakan pada kegiatan ekstrakurikuler kepramukaan, yang dilakukan oleh pembina di SMK Negeri telah direncanakan dengan baik, dengan melakukan kegiatan pelantikan anggota pramuka, baris-berbaris, berkemah dan lainnya, tanpa mengganggu proses kegiatan belajar mengajar di sekolah. Sedangkan penyebab rendahnya skor rata-rata 
pada pernyataan menyusun rencana untuk mendatangkan pelatih dalam kegiatan ekstrakurikuler kepramukaan karena pelatih kurang kompeten di bidangnya dan kurangnya keterampilan yang dimiliki pelatih.

Secara keseluruhan dapat dikatakan bahwa persepsi siswa kelas XI terhadap pengelolaan kegiatan ekstrakurikuler kepramukaan di SMK Negeri pada indikator perencanaan adalah 4,00 berada dalam kategori baik.

b. Pengorganisasian Kegiatan Ekstrakurikuler Kepramukaan di SMK Negeri Tabel 2. Distribusi Data Pengorganisasian Kegiatan Ekstrakurikuler Kepramukaan

\begin{tabular}{|c|c|l|c|c|}
\hline No & Indikator & \multicolumn{1}{c|}{ Sub Indikator } & Rata-rata & Kriteria \\
\hline \multirow{3}{*}{2} & $\begin{array}{c}\text { Pengorganisasian } \\
\text { kegiatan ekstrakurikuler } \\
\text { kepramukaan }\end{array}$ & Kejelasan tugas & 4,11 & Baik \\
\cline { 3 - 5 } & Memiliki struktur & 3,71 & Baik \\
\cline { 2 - 5 } & Kerja sama & 4,20 & Baik \\
\hline \multicolumn{2}{|c}{ Rata-rata } & $\mathbf{4 , 0 1}$ & Baik \\
\hline
\end{tabular}

Hasil pengolahan data pengorganisasian kegiatan ekstrakurikuler kepramukaan di SMK Negeri Padang jumlah skor yang paling tinggi pada pengorganisasian kegiatan ekstrakurikuler kepramukaan adalah pada bentuk kerja sama dengan skor 4,20 termasuk pada kategori baik dan skor rata-rata terendah tergolong pada pengorganisasian kegiatan ekstrakurikuler kepramukaan adalah pada struktur kegiatan ekstrakurikuler kepramukaan dengan skor rata-rata 3.71 berada di kategori baik.

Hal ini berarti bahwa kerja sama yang dilakukan oleh pembina dengan pengurus organisasi sudah terlaksana dengan baik. Skor terendah terdapat pada pengorganisasian kegiatan ekstrakurikuler kepramukaan adalah aspek pengorganisasian memiliki struktur dengan Ini disebabkan karena tugas dari masing-masing anggota di dalam struktur organisasi tidak jelas sehingga beberapa dari anggota organisasi kurang memahami tupoksi masing-masing, dan juga ada beberapa dari pengurus yang masuk ke dalam struktur organisasi kepramukaan terlihat kurang kompeten.

Secara keseluruhan persepsi siswa kelas XI terhadap pengelolaan kegiatan ekstrakurikuler kepramukaan di SMK Negeri pada indikator pengorganisasian adalah 4,01 berada dalam kategori baik. Jadi, bahwasanya pengorganisasian ekstrakurikuler kepramukaan di SMK Negeri tidak terlalu menemukan kesulitan dalam pelaksanaannya, namun masih dibutuhkan peningkatan terutama dalam hal struktur organisasi, agar pengorganisasian di dalam ekstrakurikuler kepramukaan di SMK Negeri bisa berjalan dengan lebih baik. Struktur organisasi harus terdokumentasi dengan jelas agar pembagian tugas yang telah disepakati baik itu penanggung jawab kegiatan, guru/pembina dan siswa berjalan baik sehingga tercapainya tujuan yang telah direncanakan (Nurdiana \& Prayoga, 2018). Tidak hanya itu, seharusnya pembina yang juga tergabung di dalam struktur organisasi kepramukaan sebaiknya juga harus memenuhi kualifikasi sebagai pembina pramuka.

c. Pelaksanaan Kegiatan Ekstrakurikuler Kepramukaan di SMK Negeri Tabel 3. Distribusi Data Pelaksanaan Kegiatan Ekstrakurikuler Kepramukaan

\begin{tabular}{|c|c|l|c|c|}
\hline No & Indikator & \multicolumn{1}{|c|}{ Sub Indikator } & Rata-rata & Kriteria \\
\hline \multirow{5}{*}{3} & \multirow{4}{*}{$\begin{array}{c}\text { Pelaksanaan kegiatan } \\
\text { ekstrakurikuler } \\
\text { kepramukaan }\end{array}$} & Alokasi waktu jam pelatihan pramuka & 4,34 & Baik \\
\cline { 3 - 5 } & Pengelolaan pelatihan pramuka & 4,23 & Baik \\
\cline { 3 - 5 } & Pelaksanaan pelatihan pramuka & 3,51 & Cukup Baik \\
\cline { 3 - 5 } & $\begin{array}{l}\text { Leaning by doing (belajar sambil } \\
\text { praktek) }\end{array}$ & 4,22 & Baik \\
\cline { 3 - 5 } & Sistem berkelompok & 3,40 & Cukup Baik \\
\cline { 3 - 5 } & Di alam terbuka & 3,55 & Cukup Baik \\
\cline { 3 - 5 } & Menarik dan menantang & 3,55 & Cukup Baik \\
\hline & Rata-rata & $\mathbf{3 , 8 3}$ & Baik \\
\hline
\end{tabular}

Hasil pengolahan data pelaksanaan kegiatan ekstrakurikuler kepramukaan di SMK Negeri jumlah skor yang paling tinggi pada pelaksanaan kegiatan ekstrakurikuler kepramukaan adalah pada alokasi waktu jam pelatihan pramuka dengan skor 4,34 tergolong pada kategori baik. Sedangkan skor yang paling rendah terhadap pelaksanaan kegiatan ekstrakurikuler kepramukaan adalah pada sistem berkelompok dengan skor 3,40 berada dalam kategori cukup baik.

Dalam Hal ini berarti bahwa pelaksanaan alokasi waktu jam pelatihan pramuka pada kegiatan ekstrakurikuler kepramukaan sudah dilaksanakan dengan baik. Skor terendah terdapat pada pelaksanaan kegiatan ekstrakurikuler kepramukaan adalah sistem berkelompok. Hal ini disebabkan karena kurangnya 
strategi atau pengaturan anggota pramuka oleh pembina sehingga terkadang kegiatan pramuka terlihat monoton tanpa adanya pembagian kelompok, hal ini juga disebabkan karena tenaga yang akan mengawasi kelompok/ regu pramuka juga terbilang sedikit. Padahal sistem kelompok juga merupakan metode yang baik dilakukan untuk membuat pembelajaran menjadi lebih menyenangkan. Sebagaimana yang dijelaskan bahwa metode kepramukaan meliputi pengamalan Kode Kehormatan Pramuka, belajar sambil mempraktekkan, sistem dilakukan secara berkelompok, kegiatan menantang peserta dan meningkat dan mengandung unsur-unsur pendidikan yang sesuai dengan perkembangan jasmani dan rohani anggota, kegiatan dilaksanakan alam terbuka, sistem tanda kecakapan, dan sistem satuan terpisah(Utomo, 2015)

Secara keseluruhan skor persepsi siswa kelas XI terhadap pengelolaan kegiatan ekstrakurikuler kepramukaan di SMK Negeri pada indikator pelaksanaan adalah 3,83 berada dalam kategori baik.

\section{d. Pengawasan Kegiatan Ekstrakurikuler Kepramukaan di SMK Negeri}

Tabel 4. Distribusi Data Pengawasan Kegiatan Ekstrakurikuler Kepramukaan

\begin{tabular}{|c|c|l|c|c|}
\hline No & Indikator & \multicolumn{1}{|c|}{ Sub Indikator } & Rata-rata & Kriteria \\
\hline \multirow{4}{*}{4} & $\begin{array}{c}\text { Pengawasan kegiatan } \\
\text { ekstrakurikuler } \\
\text { kepramukaan }\end{array}$ & $\begin{array}{l}\text { Pengawasan/monitoring melalui } \\
\text { penilaian kegiatan ekstrakurikuler } \\
\text { pramuka }\end{array}$ & 4,15 & Baik \\
\cline { 2 - 5 } & Melakukan evaluasi & 3,95 & Baik \\
\hline \multicolumn{2}{|c|}{ Rata-rata } & $\mathbf{4 , 0 5}$ & Baik \\
\hline
\end{tabular}

Hasil pengolahan data pengawasan kegiatan ekstrakurikuler kepramukaan di SMK Negeri jumlah skor paling tinggi pada pengawasan kegiatan ekstrakurikuler kepramukaan adalah pada pengawasan/monitoring melalui penilaian kegiatan ekstrakurikuler pramuka dengan skor 4,15 berada dalam kategori baik. Sedangkan dapat dilihat skor yang paling rendah pada pengawasan kegiatan ekstrakurikuler kepramukaan di SMK Negeri adalah pada melakukan evaluasi dengan rata-rata skor 3,95 tergolong kategori baik.

Hal ini menunjukkan pengawasan kegiatan ekstrakurikuler kepramukaan di SMK Negeri telah berjalan dengan baik. Yang berperan mengawasi ekstrakurikuler adalah pembina di bawahi oleh arahan wakil kepala sekolah bidang kesiswaan. Pengawasan dilakukan pada saat kegiatan ekstrakurikuler berlangsung yaitu setelah jam pelajaran berakhir (Septiani \& Wiyono, 2012). Oleh karena itu, pengawasan kegiatan ekstrakurikuler kepramukaan yang dilakukan oleh pembina di SMK Negeri telah diawasi dengan baik

Skor terendah terdapat pada pengawasan kegiatan ekstrakurikuler kepramukaan adalah aspek pengawasan melakukan evaluasi dengan skor 3,95 berada dalam kategori baik. Hal ini disebabkan karena pembina jarang melakukan evaluasi terhadap pelaksanaan kegiatan ekstrakurikuler kepramukaan setiap minggu.

Dari penjelasan diatas dapat dilihat bahwasanya pengawasan ekstrakurikuler kepramukaan di SMK Negeri tidak terlalu menemukan kesulitan, namun masih perlu peningkatan agar pengawasan yang dilakukan bisa berjalan dengan lebih baik. Mengukur tingkat kepuasan konsumen disebut juga dengan mengevaluasi reaksi. Jika peserta didik merasa termotivasi, terpengaruhi, tertarik dan senang maka program tersebut berhasil dan sebaliknya jika reaksi yang diberikan tidak berpengaruh maka program tersebut gagal (Triana, 2020).

Secara keseluruhan skor pengelolaan kegiatan ekstrakurikuler kepramukaan di SMK Negeri pada indikator pengawasan adalah 4,05 berada pada kategori baik.

e. Rekapitulasi Persepsi Siswa Kelas XI terhadap Pengelolaan Kegiatan Ekstrakurikuler Kepramukaan di SMK Negeri

Tabel 5. Rekapitulasi Persepsi Siswa Kelas XI terhadap Pengelolaan Kegiatan Ekstrakurikuler Kepramukaan di SMK Negeri

\begin{tabular}{|c|l|c|c|}
\hline No & \multicolumn{1}{|c|}{ Indikator } & Rata-rata & Kategori \\
\hline 1 & Perencanaan kegiatan ekstrakurikuler kepramukaan & 4 & Baik \\
\hline 2 & Pengorganisasian kegiatan ekstrakurikuler kepramukaan & 4,01 & Baik \\
\hline 3 & Pelaksanaan kegiatan ekstrakurikuler kepramukaan & 3,83 & Baik \\
\hline 4 & Pengawasan kegiatan ekstrakurikuler kepramukaan & 4,05 & Baik \\
\hline \multicolumn{2}{r}{ Rata-rata } & $\mathbf{3 , 9 7}$ & Baik \\
\hline
\end{tabular}


Tingkat capaian tertinggi dari persepsi siswa kelas XI terhadap pengelolaan kegiatan ekstrakurikuler kepramukaan di SMK Negeri yaitu indikator pengawasan kegiatan ekstrakurikuler kepramukaan dengan rata-rata skor 4,05 berada dalam kategori baik, sedangkan tingkat capaian terendah terdapat pada indikator pelaksanaan kegiatan ekstrakurikuler kepramukaan dengan rata-rata skor 3,83 berada dalam kategori baik.

Jadi secara keseluruhan disimpulkan bahwa persepsi siswa kelas XI terhadap pengelolaan kegiatan ekstrakurikuler kepramukaan di SMK Negeri berada di kategori baik dengan perolehan skor 3,97.

\section{Kesimpulan}

Berdasarkan hasil penelitian tersebut disimpulkan bahwa Persepsi Siswa kelas XI Terhadap Pengelolaan Kegiatan Ekstrakurikuler Kepramukaan di SMK Negeri dilihat pada aspek perencanaan sudah tergolong baik, pada aspek pengorganisasian telah berada pada kategori baik, pada aspek pelaksanaan berada dalam kategori baik, dan pada aspek pengawasan sudah terkategori baik. Oleh sebab itu, perlu adanya peningkatan terhadap pengelolaan kegiatan ekstrakurikuler kepramukaan di SMK Negeri agar program yang telah direncanakan bisa terlaksana dengan baik dan dapat mencapai tujuan yang diinginkan.

\section{Daftar Rujukan}

KEMENDIKBUD RI. (2014). Permendikbud Nomor 81A 2013. Implementasi Kurikulum Kurikulum, 1, 1-97.

Nurdiana, M., \& Prayoga, A. (2018). Fungsi-Fungsi Manajemen dalam Kegiatan Ekstrakurikuler Pramuka di Madrasah. Madrasa: Journal of Islamic Educational Management, 1(December 2018), 9-15. https://doi.org/10.32940/mjiem.v1i0.2

PERMENDIKBUD R.I No.62 Tahun 2014. (2014). PERMENDIKBUD R.I No.62 Tahun 2014 tentang Ekstrakulikuler pada pendidikan dasar dan pendidikan menengah. 1-4.

Republik Indonesia. (2010). Undang-Undang Republik Indonesia Nomor 12 Tahun 200 Tentang Gerakan Pramuka. Undang-Undang Republik Indonesia, 24 NOVEMBER, 1-23.

Septiani, I., \& Wiyono, B. B. (2012). Manajemen kegiatan ekstrakurikuler dalam meningkatkan kualitas sekolah. Jurnal Manajemen Pendidikan, 23(5), 424-433.

Triana, H. (2020). Evaluasi Program Ekstrakurikuler Pramuka Sekolah Menengah Kejuruan. September.

Utomo, J. (2015). Pelaksanaan Ekstrakurikuler Pramuka di SD Negeri IV wates. Pendidian Guru Sekolah Dasar, 2(4), 01-10. 